\title{
Adult Swyer-James-MacLeod syndrome: report of two cases and review of the literature
}

\author{
Luigi Abate, ${ }^{1}$ Paolo Biagi, ${ }^{1}$ Domenico Fabbrini, ${ }^{1}$ Piero Nardi ${ }^{2}$ \\ ${ }^{1}$ Division of Internal Medicine; ${ }^{2}$ Division of Radiology, Associated Hospitals in Val di Chiana, Montepulciano (SI), Italy
}

\begin{abstract}
Swyer-James-MacLeod syndrome is a rare clinico-pathological entity associated with post-infectious bronchiolitis obliterans occurring in childhood. It is characterized by hypoperfusion of pulmonary parenchyma resulting into a peculiar radiological pattern, such as a translucent or hyperlucent unilateral lung. Typically, this disorder is diagnosed in childhood during a workup for recurrent respiratory infections, but sometimes patients who have little or no sequelae bronchiectasis remain asymptomatic until adulthood, when diagnosis is made either incidentally or with symptoms. We present two cases of adult patients for whom diagnosis was made in the course of the workup for dyspnea.
\end{abstract}

\section{Introduction}

Swyer-James-MacLeod syndrome (SJMS) is a rare condition defined by an acquired hypoplasia of the pulmonary arteries, generally considered to be a post-infectious complication of viral bronchiolitis obliterans (BO) or pneumonia acquired during early childhood. The radiological pattern is characterized by hyperlucency of a lobe, or the entire lung with decreased vascular markings, in the absence of any bronchial obstruction. ${ }^{1,2}$ It may be associated or not to bronchiectasis.

It manifests itself clinically with frequent episodes of bronchitis and/or bronchopneumonia with or without respiratory failure during childhood. It may remain misdiagnosed till adulthood when the diagnosis may be made incidentally or sometimes with very important symptoms associated with defects of the pulmonary function test. ${ }^{3}$

In these patients the diagnosis of SJMS entails the

Correspondence: Luigi Abate, via Cocconi 3, 53045 Montepulciano (SI), Italy.

E-mail: villabercio@tiscali.it ; 1.abate@us17.toscana.it

Key words: hypoplastic pulmonary arteries, bronchiolitis obliterans.

Received for publication: 9 August 2013.

Revision received: 3 September 2013.

Accepted for publication: 6 September 2013.

This work is licensed under a Creative Commons Attribution NonCommercial 3.0 License (CC BY-NC 3.0).

CCopyright L. Abate et al., 2014

Licensee PAGEPress, Italy

Italian Journal of Medicine 2014; 8:127-131

doi:10.4081/itjm.2013.424 exclusion of other causes of unilateral hypertranslucency of the lung, such as lung bullae, cysts or congenital vascular defects or pulmonary embolism.

We present two cases of adult patients for whom the diagnosis of the SJML syndrome was made in the course of the workup for dyspnea and in which volumetric high resolution computed tomography (vHRTC) with post processing to maximum intensity projection (MIP) clearly demonstrated the hypoplastic pulmonary vascular defects.

\section{Case Reports}

\section{Case \#1}

C.D., a 68-year-old woman, cigarette smoker (25 packs/year), admitted to the Department of Internal Medicine for dyspnea [modified Medical Research Council (m MRC) scale=4]. Her medical history was not remarkable with the exception of recurrent lower respiratory tract infections in childhood, but in the last two years she had progressive dyspnea, productive cough with scant amount of mucoid sputum, weight reduction and a few days before the admission decumbent edema.

The physical examination revealed an undernourished woman with dyspnea at rest, a remarkable reduction of vesicular murmur over the entire left hemithorax and diffuse wheezing; and persistent crackles at the lung bases were present at chest auscultation.

The blood pressure was $100 / 80 \mathrm{mmHg}$; heart rate was $82 / \mathrm{min}$ and regular; respiratory rate was $22 / \mathrm{min}$ and morning oral temperature was $36.4^{\circ} \mathrm{C}$. Oxigen saturation in room air was $90 \%$. At the left lower sternal border and the cardiac apex S3 and a blowing grade III/VI holosystolic murmur were heard. Ankle edema was present. 
Routine blood tests were normal. Erythrocyte sedimentation rate $(\mathrm{ESR})$ was $=32$ and $\mathrm{C}$-reactive protein $=4.1$, white blood counts $(\mathrm{WBC})=9100(72 \%$ neutrophils), IgG, IgM, IgA, and IgE values were within the normal range.

The level of serum pro-brain natriuretic peptide was increased $(2432 \mathrm{ng} / \mathrm{mL}-$ normal value $<200$ $\mathrm{ng} / \mathrm{mL}$ ).

Pulmonary function tests (PFT) based on helium dilution were characterized by very severe obstructive abnormalities with lung hyperinsufflation [residual volume $(\mathrm{RV})=153 \%$, Motley index $=175 \%$ ]; and a moderate decrease of the single-breath diffusing capacity of the lung for carbon monoxide (DLCO) that was 9.80 in absolute value (52.3\% of predicted value); diffusing capacity divided by the alveolar volume (DLCO/VA) was 3.1 in absolute value ( $68.7 \%$ of predicted).

The arterial blood gas (ABG) showed a decrease of arterial oxygen tension $\left(\mathrm{PaO}_{2}=62 \mathrm{mmHg}\right)$ with normal carbon dioxide tension $\left(\mathrm{PaCO}_{2}=38.9 \mathrm{mmHg}\right)$ and acidity ( $\mathrm{pH}=7.39)$.

Elecrocardiogram (ECG) showed tachycardia with a pulmonary $\mathrm{P}$ wave in the inferior leads.

Transthoracic echocardiography (TTE) revealed right ventricular enlargement and systolic dysfunction, pulmonary hypertension (estimated systolic pulmonary artery pressure $=50 \mathrm{mmHg}$ ) associated with tricuspid regurgitation.

Chest X-rays showed hyperlucency of the left lung, with air-trapping on expiration and minimal fibrosis in the lower left lobe (Figure 1). v-HRTC with
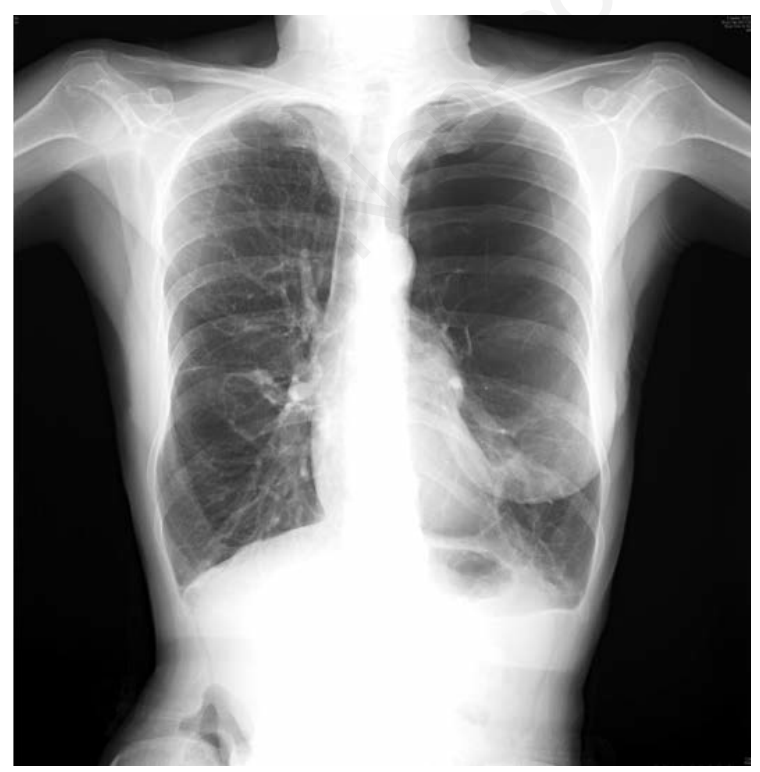

Figure 1. Case \#1. Chest X-rays. Minimal hyperinsufflation of the left hemithorax, hyperlucency of the left lung and right middle lobe. Marked reduction of the vascular pattern. Limited areas of basal fibrosis.
MIP clearly showed an hypoplasia of the pulmonary arteries of the entire left lobe, of the middle right lobe and to a minor extent of the right upper lobe. The remaining right lobe was affected by centrilobular emphysema (Figure 2).

The patient was treated with diuretics, ace-inhibitors, steroids, $\beta 2$-agonists, anticholinergic agents and antibiotics on empirical basis (levofloxacin), improvement and was finally discharged.

\section{Case \#2}

A.B., a 38-year-old woman, nonsmoker, was admitted in the Medical Department with fever, dyspnea and tachycardia. She moved from southern Italy to our country one year before.

Her medical history revealed that in childhood she was affected by asthma and pollen allergy, which disappeared after puberty. She reported no asthmatic episodes or allergic rhinitis after age 13 .

Her physical examination showed a well-preserved woman, mild dyspnea ( $\mathrm{m}$ MRC scale $=2$ ).

Chest crackles and wheezes in the right lung field and in and marked expiratory reduction of vesicular murmur were identified in the left lung.

The blood pressure was $130 / 80 \mathrm{mmHg}$; heart rate was $100 / \mathrm{min}$ and regular; respiratory rate was $20 / \mathrm{min}$ and morning oral temperature was $38.4^{\circ} \mathrm{C}, \mathrm{O}_{2}$ saturation in room air was $93 \%$. Cardiac auscultation was normal. Nothing else was relevant. Laboratory data revealed $\mathrm{ESR}=34, \mathrm{WBC}=9100$ ( $78 \%$ neutrophils),

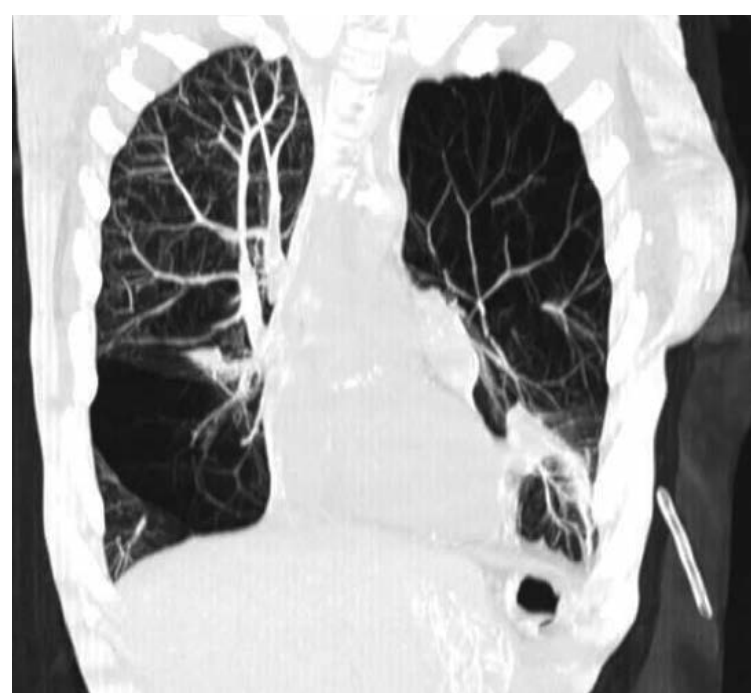

Figure 2. Case \#1. Volumetric high resolution computed tomography and maximum intensity processing: the coronal reconstruction shows a marked reduction of lung vessel lumen from the ilum to the periphery of the left and middle lobe of the right lung. Minimal basal bilateral fibrosis is also evident. 
whereas the other routine parameters were in the normal range.

ECG was normal with the exception of mild tachycardia (100/min).

PFTs based on body pletismography were characterized by very severe obstructive abnormalities defect with lung overinsufflation $(\mathrm{RV}=188 \%$, Motley index $=$ $159 \%$ ).

The blood gas analysis showed normal arterial oxygen tension $\left(\mathrm{PaO}_{2}=74.8 \mathrm{mmHg}\right)$ with normal carbon dioxide tension $\left(\mathrm{PaCO}_{2}=38 \mathrm{mmHg}\right)$ and acidity $(\mathrm{pH}=7.38)$.

The TTE was normal and in particular no dilatation was found in the right sections. The chest X-rays showed hyperlucency of the left lung (Figure 3 ) as confirmed by v-HRCT (Figure 4).

She was treated with a steroid therapy, levofloxacin and ceftriaxone on empirical basis, and her clinical picture improved.

\section{Discussion and Conclusions}

Swyer-James-MacLeod syndrome is a rare condition which was first described in a child by Swyer and James in $1953,{ }^{4}$ one year later MacLeod reported the same syndrome in 9 patients. ${ }^{5}$

Radiographically this syndrome is characterized by hyperlucency of a lobe, or the entire lung with decreased vascular markings with no bronchial obstruction. Areas of bronchiectasis may be present.

It is generally believed to be a post-infectious com-

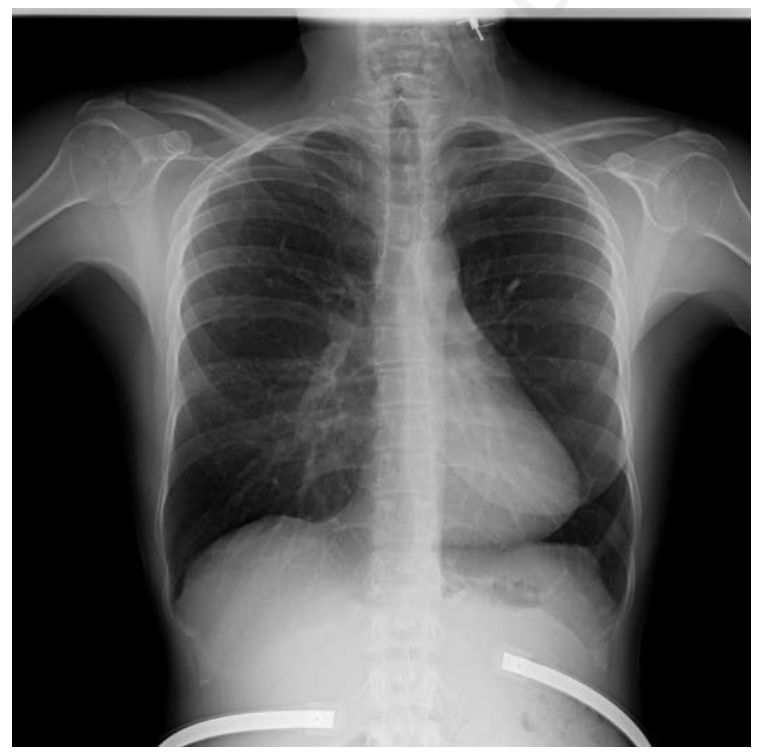

Figure 3. Case \#2. Chest X-rays. Decreased volume of the right emithorax and unilateral hyperlucency of the left lung with reduced vascular pattern. plication of viral bronchiolitis or pneumonia acquired during early childhood, ${ }^{6}$ associated mostly with Paramyxovirus morbillivirus, Bordetella pertussis, Mycobacterium tuberculosis, Mycoplasma pneumoniae, influenza $A$ and adenovirus types 3, 7 and 21.2,3,7

Bronchiolitis obliterans is presumed to result in inflammation and fibrosis in the walls and contiguous tissue of the membranous and respiratory bronchioles with a narrowing of their lumina. ${ }^{8}$

Interalveolar septa fibrosis causes obliteration of the pulmonary capillary bed and diminishes the blood flow to the major pulmonary artery segments, which in turn results in an hypoplastic arterial development. In addition, the reduction in ventilation causes a compensatory decrease in perfusion via vasoconstriction. ${ }^{9,10}$

The hyperexpansion of the terminal air sacs, secondary to bronchiolar obstruction of the peripheral airways, offers additional mechanical resistance to the circulation of the blood flow through the alveolar capillaries and contributes to the atrophy of the vascular bed. ${ }^{11}$

Hypoplasia of the pulmonary arteries is a consequence of this decrease in the blood flow.

Bronchiectasis may be part of the clinical picture, being secondary to the atelectasis and scarring induced by $\mathrm{BO}$ or to the damage of both bronchioles and bronchi induced by viral infection, ${ }^{12,13}$ but there is evidence that bronchiectasis are not an invariable finding nor a necessary component of SJMS. ${ }^{14}$

Clinically SJMS manifested itself with frequent episodes of bronchitis and/or bronchopneumonia associated with respiratory failure in childhood. Diagnosis can be made in this this age group with a simple
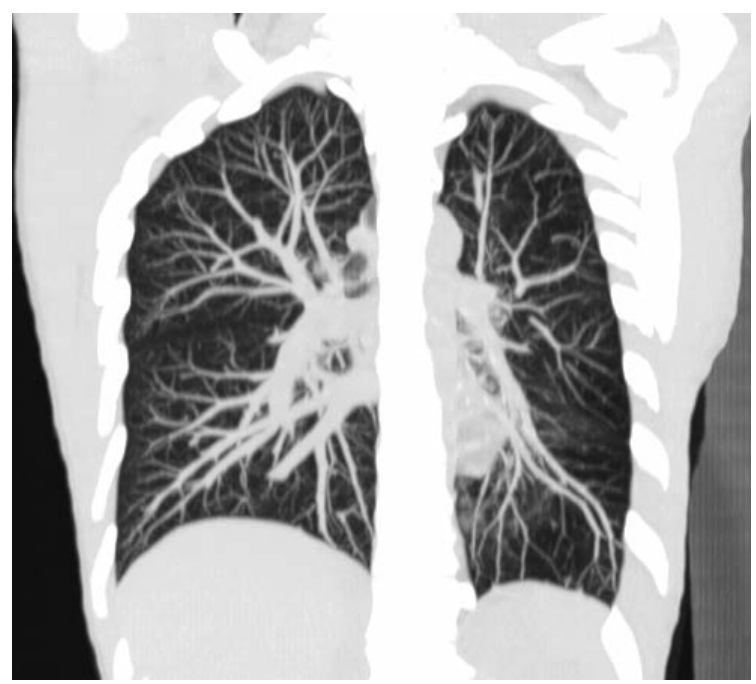

Figure 4. Case \#2. Volumetric high resolution computed tomography and maximum intensity processing: the coronal reconstruction clearly shows a more evident hypoplasia of left lung vessels, the left branch of pulmonary artery measuring about $8 \mathrm{~mm}$. 
chest radiography. It's more rare in adults and in this case the differential diagnosis must be made considering less common cases of localized hyperlucency of the lung, as in localized emphysema or congenital hypoplastic pulmonary artery. ${ }^{15-17}$

The key diagnostic factor is the demonstration of a reduced pulmonary vascular tree which corresponds to the area of hyperlucency. What could be seen in the past with pulmonary angiography or CT angiography can now be identified without iodinated constrast agents with v-HRCT and MIP reconstruction, that allow us to make a reliable diagnosis. ${ }^{18-21}$ In fact with the advent of multidetector CT, we may obtain, with lower X-rays exposure, up to 64 slices $(0.5 \mathrm{~mm}$ thin) in a single rotation and in a single breath hold, thereby offering a volumetric acquisition of data without artifacts. Additionally, upgraded computer hardware and software have improved image quality and offer a better two and three dimensional reconstruction.

Although, SJMS is conventionally considered as a unilateral disease, the availability of cross-sectional imaging has changed this definition. It is now increasingly evident that SJMS is not a unilateral condition, but may have a wide spectrum of bilateral involvement. ${ }^{22}$ This was well demonstrated in our first case in which the left lobe and large parts of the middle and upper right lobe were involved.

Most patients with SJMS are symptomatic at initial presentation. Shortness of breath on exertion is the most frequent symptom but also hemoptysis from a bronchial vessel or chronic obstructive pulmonary disease can be rarely found at initial presentation. ${ }^{23}$

Our two cases do not differ clinically from those described in the literature diagnosed in adult life. Both patients typically showed frequent lower respiratory tract infections during childhood and were unaware of their disease.

However, the first patient showed clinical and instrumental signs of pulmonary hypertension and right heart failure: actually SMJS may be the presenting sign of right heart failure, ${ }^{10,24}$ and is generally considered to be the consequence of the reduction of the lung vascular bed. However, in our patient, the heavy smoking habit may have contributed to induce the centrilobular emphysema.

In conclusion, SMJS is a syndrome that may be discovered incidentally in adult life following e.g. an workup for respiratory symptoms. The presenting symptoms are nonspecific: coughing, wheezing, frequent episodes of lower respiratory tract infections or signs of a right heart failure may prompt to perform chest X-rays, which indicate more or less extensive areas of increased lucency in the lung.

The use of chest $X$-rays may lead to underestimate the prevalence of SMJS. The diagnosis must be based on $\mathrm{CT}$, which may demonstrate the typical pattern of the architectural changes of the lung, the hypoplasia of the vascular area involved and eventually the associated bronchiectasis. Today v-HRCT with MIP reconstruction can provide us all the necessary and sufficient information to make the diagnosis with significant evidence.

\section{References}

1. Tortajada M, Gracia M, García E, Hernández R. Diagnostic considerations in unilateral hyperlucency of the lung (Swyer-James-MacLeod syndrome). Allergol Immunopathol (Madr) 2004;32:265-70.

2. Fregonese L, Girosi D, Battistini E, et al. Clinical, physiologic, and roentgenographic changes after pneumonectomy in a boy with MacLeod/Swyer-James syndrome and bronchiectasis. Pediatr Pulmonol 2002;34:412-6.

3. Capela C, Gouveia P, Sousa M, Regadas MJ. Adult diagnosis of Swyer-James-MacLeod syndrome: a case report. J Med Case Rep 2011;5:2-4.

4. Swyer PR, James GC. A case of unilateral pulmonary emphysema. Thorax 1953;8:133-6.

5. MacLeod WM. Abnormal transradiancy of one lung. Thorax 1954;9:147-53.

6. Erkasar CF, Caglar CE, Koray D, Ilgin KN. Bilateral Swyer-James (MacLeod's) syndrome. Indian J Pediatr 2002;68:433-5.

7. Schlesinger C, Veeraraghavan S, Koss MN. Constructive (obliterative) bronchiolitis. Curr Opin Pulm Med 1998;4:288-93.

8. Schlesinger C, Meyer CA, Veeraraghavan S, Koss MN. Constrictive (obliterative) bronchiolitis: diagnosis, etiology, and a critical review of the literature. Ann Diagn Pathol 1998;2:321-34.

9. Sulaiman A, Cavaille A, Vaunois B, Tiffet O. SwyerJames-MacLeod syndrome; repeated chest drainages in a patient misdiagnosed with pneumothorax. Interact CardioVasc Thorac Surg 2009;8:482-4.

10. Hajsadeghi SH, Chitsazan M, Pouraliakbar HR, Jafarian Kerman SR. Swyer-James-MacLeod syndrome presenting with pulmonary hypertension. Iranian Cardiovasc Res J 2010;4:134-8.

11. Mathur S, Gupta SK, Sarda M, Jaipal U. Swyer-JamesMacLeod syndrome with emphysematous bulla. J Indian Med Assoc 1995;93:150-4.

12. Shimamoto V, Shimamoto H, Matsuura Y, et al. A case of Swyer-James syndrome, with reference to pathophysiologic and etiologic aspect. Hiroshima J Med Sci 1986; 35:163-6.

13. Thuribeck WM. Chronic airflow obstruction. In: Thurlbeck WM, ed. Pathology of the lung. New York: Thieme Medical; 1988. pp 519-575.

14. Moore AD, Godwin JD, Dietrich PA, et al. Swyer-James syndrome: CT findings in eight patients. AJR Am J Roentgenol 1992;158:1211-5.

15. Fraser RS, Müller NL, Colman N, Pare PD. Developmental anomalies affecting the pulmonary vessels. In: Fraser RS, Pare PD, eds. Fraser and Pare diagnosis of disease of the chest. 4th ed. Philadelphia: WB Saunders Company; 1999. pp 637-675.

16. Sharma A, Bieuei F, Dillon E. Agenesis of the left pul- 
monary artery with PDA and hypoplasia of left lung. Appl Radiol Online 2004;6:33.

17. Sunaval AJ, Thacker HP, Khanna JN. Left pulmonary artery hypoplasia presenting with unilateral hyperluscent lung. J Assoc Physicians India 2011;59:179-81.

18. Lucaya J, Gartner S, Garcia-Pena P, et al. Spectrum of manifestations of Swyer-James-MacLeod syndrome. J Comput Assist Tomogr 1998;22:592-7.

19. Gómez Belda AB, Martínez-Moragón E, Fernández Fabrellas E. Swyer-James syndrome: diagnostic contributions of helical computerized tomography. Arch Bronconeumol 2000;36:421-2.

20. Chuang TL, Wang YF, Lai CL. Ventilation-perfusion SPECT/CT in diagnosing Swyer-James (MacLeod) sindrome. Tzu Chi Med J 2010;22:213-8.

21. Kasthoori JJ, Kumar G, Wastie ML. Volumetric high- resolution computed tomography of the lung-a comparison to standard acquisition in diffuse lung disease. JHK Coll Radiol 2005;8:233-43.

22. Ghossain MA, Achkar A, Buy JN, et al. Swyer-James syndrome documented by spiral CT angiography and high resolution inspiratory and expiratory CT: an accurate single modality exploration. J Comput Assist Tomogr 1997;21:616-8.

23. Abba AA, Al-Mobeireek AF. Clinical spectrum of Swyer-James-MacLeod syndrome in adults. Saudi Med J 2003;24:195-8.

24. Fernández Fabrellas E, Marín González M, Almenar Bonet L, Blanquer Olivas R. Severe pulmonary hypertension: a feature of Swyer-James syndrome? Monaldi Arch Chest Dis 1997;52:140-1. 